\title{
The Approach of Cultivation College Students Safety Culture Based on the Academic Advantage
}

\author{
Dan Mei \\ Wuhan University of Science and Technology \\ Hubei Wuhan, China. \\ meidan666@163.com \\ Long Yuan \\ Wuhan University of Science and Technology \\ Hubei Wuhan, China.
}

\author{
Meng Wen \\ Wuhan University of Science and Technology \\ Hubei Wuhan, China
}

\author{
Yaoxuan Tao \\ Wuhan University of Science and Technology \\ Hubei Wuhan, China. \\ 1039475911@qq.com
}

\begin{abstract}
To strengthen the safety culture of college students, training their safety awareness, safety concepts and safety knowledge is a new requirement in the new period of national construction and development of professional talents. That plays important roles in promoting the secure and harmonious development of the whole society. This study elaborated the significances to strengthening the education of safety culture of college students, analyzed the current status of safety/security culture education in colleges and universities. And based on those analyses, we presented an effective approach of safety culture education for college students that is cultivation college students' safety culture base on the academic advantage. Our study aims to improve the safety culture quality of college students, and promote the quality of personnel training of university through optimizing the education course system and building safety culture education platform etc.
\end{abstract}

Keywords-College students/ University student ;Safety Culture; Education; Approach; cultivation

\section{INTRODUCTION}

Safety culture is the concept of security, safety awareness and the behavior under the guidance of the general term, mainly including the safety concept, behavior safety, system safety and process safety.[1] With the continuous development of social economy, security related to the whole country, especially the industry safety production. Countries put forward to make clear a requirement, "the people's Republic of China Law on safety in production" (2014 Amendment) Regulations:" mines, metallurgy, construction, road transportation and dangerous goods production, management, storage units should set up safety management institutions or equipped with full-time personnel for the administration of production safety ", which puts forward higher requirements for talents training in engineering universities, students should not only master the production knowledge of the industry, but also have the knowledge of safety production and safety management. Therefore, it is of great significance to carry out

This paper is the stage results of Hubei Province Education Department of education teaching and research project "based on the discipline advantage of College Students' safety culture cultivation system research and practice(project number 2015230)", Wuhan University of science and technology teaching and research project ( project number YJG 201529,2013Z047). the safety culture education of college students and improve the safety culture knowledge and literacy of university students.

\section{A. Enhance national security literacy.}

College students are pillars of the future construction and development of national, at the same time, the university is the best period for students to learn knowledge and skills, It is an important stage of human's personality and psychological quality gradually moving towards maturity, strengthen the safety education for college students will help to enhance the awareness of national security and safety quality and to lay the cornerstone for the construction of safety culture in society.

\section{B. Strengthen personal safety awareness.}

Safety culture education helps to improve college students' personal safety awareness and prevention awareness, especially in the production process in the industry in future, firmly establish a sense of safety, standardize the behavior of individual security, form the system of safety management and to avoid the occurrence of work, production and life as far as possible.

\section{Meet the needs of employment oriented.}

Constantly adapt to the requirements of the employer to safety production and safety operation. Cultivate high-quality personnel which have a solid professional knowledge, safety consciousness and safety management knowledge, broaden the students' employment ability to achieve schools, enterprises, social win-win situation.

\section{The CURRENT SituATION OF SAFETy CULTURE EDUCATION IN COLLEGES AND UNIVERSITIES}

At present, most domestic universities have not yet been carried out safety education for college students but only personal safety education who's functions mainly concentrated in ideological education department and security department, such as Wuhan University of science and technology, Shijiazhuang University of economics, Chongqing Institute of 
science and Technology University, they take "safe campus" as a platform to implement the education of life safety, mental health, network security and national defense [3], but does not involve the industry production and operation management, safety and occupational health risk education. Only a few colleges and universities have carried out a more professional and wider range of safety culture education, the main reasons are the following aspects:

\section{A. Lack of ideological knowledge.}

Security is a broad concept, which is put forward from the point of view of human body and something that is directly or indirectly related to human body and mind. [4] The safety education of students is merely for direct and indirect safety of person, including life, property, psychological and fire safety but has not been involved in the education of safety culture, and it also has not caused enough attention in the thought.

\section{B. Lack of appropriate conditions.}

Security culture has broad and narrow sense, it involves a wide range of content which needs a certain basic support to carry out the education and training of safety culture, some colleges and universities do not have enough advantages to carry out safety culture education. On the other hand, the education of safety culture cultivation target is not clear, the training standards are not unified, the training ways are not clear, the training content is not advanced, failed to form a whole organic system and failed to catch up with the country's policy direction and industry demand

\section{Students' acceptance is not high.}

The majority of students stayed in unilateral to the importance of safety culture understanding and limited to the level of their own safety, lacking of Safety knowledge in all fields of industry and lacking of practice and perception that lead to the low acceptance of students in the safety culture education.

\section{THE APPROACH OF CUlTIVATION COLlEge STUDENTS \\ SAFETY CULTURE BASE ON THE ACADEMIC ADVANTAGE}

Wuhan University of Science and Technology is one of the first units to become the national first level discipline "safety science and Engineering" doctoral degree granting authority. In 2012, the subject was evaluated as the key subject of Hubei Province, and it has obvious advantages in the field of safety. In view of the present situation of the lack of safety culture in college students, our school rely on the advantages of safety science and engineering discipline construction, use the professional teachers, research results, experimental platform and other advantages of resources, radiate safety education to other major in the whole school to develop safety culture education and practice for the students in our school. Combine with the characteristics of our school and take the employment demand as the guidance, optimize the curriculum system of safety culture education, build the school safety culture training platform, expand the professional education to the cultural quality education and promote the popularity of safety knowledge education and enhance students' safety culture.

\section{A. Improving the ideological understanding}

Updating educational ideas is the prerequisite and fundamental of all reforms and development, only by understanding in thought can we penetrate the reform essence into all aspects of personnel training. Marx presented in the understanding of the theory that knowledge comes from practice, and counterproductive in practice. The problem of the mind is the lack of understanding of the mind; it is the lack of awareness of safety culture literacy of the teaching administrators, teachers and students that results in the shortage of students' safety culture literacy. Only by constantly updating the ideological concept and achieving a consensus on the cultivation of college students' safety culture literacy can we better enhance the students' safety culture literacy.

\section{B. Optimizing the curriculum system of safety culture education}

Combined with the school characteristics and employment oriented, based on the advantages of security disciplines to build a "1+4" curriculum system, namely, a core, the four direction of the safety culture education curriculum system. Our school of safety science and engineering is based on metallurgical industry background, and take the industrial ventilation and occupation harm, the metal mine safety technology , metallurgical equipment fault diagnosis and risk control, blasting safety theory and technology, green manufacturing and metallurgical enterprise production safety management as the main direction, rely on the background of the metallurgical industry for the school personnel training services, form the safety education of the chain in the metallurgical industry, by the way broaden the students' knowledge, set up the four professional direction about safety science, security technology, safety management, public security, set elective module and set up safety system engineering, safety ergonomics, safety principles to enhance students' safety culture quality education, cultivate the talents with rich knowledge background.

\section{Constructing the safety culture literacy education platform for College Students}

Build "Online + offline" safety culture education platform. Using modern information technology tools to promote the construction of a variety of teaching carrier, form the "mutual accommodation, mutual complement, mutual improvement" education platform with the combination of "online" and "offline". The "Online" platform is the carrier of innovative teaching, set up an online classroom, micro classroom and safety education forum, replenish academic frontier, discusses the social hot issues, through in the surrounding chemical explosion, mining accidents, fire case to analysis the hidden dangers behind the accident and began real time case teaching; invite experts to explain and comment the sudden accident and use "online" platform to discuss, expand the students learning time and space limitations and improve students' interest in learning.

"Offline" platform means opening elective course for all the students in school. Relying on the school public elective course platform, construct safety characteristics of education curriculum, set up school elective course "College Students' 
safety culture" which covers the basic safety culture and professional safety education that can not only cultivate students public safety culture, enhance students' safety consciousness and safety knowledge, but also impart the professional safety knowledge that are necessary for the excellent talents to help the students to resist the safety accidents in the production of the industry. Combined with the practical aspects of safety training, students should go out of the campus to participate in various activities, especially engineering students who face a variety of industry risk when go to the site, factories, workshops and other, we must strengthen the safety education in the process of students' practical, combine the "offline" education with the practice and safety training, form the effective combination of "theory + practice" to help students quickly grasp the basic knowledge of industry safety, such as hazard identification, toxic and harmful factors in the protection, occupational risk education and other content.

\section{Constructing the campus safety culture atmosphere}

Strengthen the publicity of campus safety culture, sort out the safety tips and small experience into a booklet to make teachers and students keep the memory enhancement, by the way play advantage disciplines, to carry out safety seminar, safety laws and regulations knowledge contest and other activities to penetrate further safety culture, Construct the cultural atmosphere of "everyone learn safety" [5] .Hold the knowledge contest of safety regulations and active competition form to increase students' interest in participation, combine with practice, hold fire and firefighting exercise, encourage more teachers and students to care about and participate in the exercise, etc. The create of the Campus atmosphere make students remind the importance of safety at all time and consciously accept safety education, which is more conducive to enhance student safety awareness and safety culture [6].

\section{E. Actively promote the normalization and institutionalization of College Students' safety education.}

Schools should move the contents of safety education in class and put it into the teaching plan, requires like other compulsory courses, unified curriculum and unified examination to make it systematic and standardized. In addition, improve teachers' professional level of safety knowledge, making them is not only responsible for the task of teaching students professional knowledge, but also have the responsibility and obligation to teach students the public safety knowledge to help students improve the emergency ability of avoiding disaster. For example, teaching about computer security, network security in computer courses; teaching some field survival, distress, emergency rescue knowledge in the geological field practice; teaching related fire and explosion safety knowledge in a series of experimental course; teaching the protection of intellectual property rights of knowledge in the graduation design and graduation thesis. In short, we should make the safety education of relevant knowledge fusion to professional course teaching, to accept the education of professional knowledge and safety knowledge at the same time, enhance the self-protection and security capacity, and improve the overall quality comprehensively. At the same time, improve the safety education system, the management of the campus order, laboratory and chemical safety management system according to the laws and regulations. And then we have to implement the security responsibility system. In accordance with the relevant rules and regulations to implement the responsible person of the relevant responsibilities, the implementation of the security responsibility to the individual, so that each department and everyone is concerned about security issues, to establish the awareness that safe is not small matter, perfecting social insurance system.

\section{SUMMARY}

Safety education for college students is a long-term systematic project, relying on the advantage of discipline and constantly improve administrators, teachers and students thinking and understanding, through the promotion of safety culture education curriculum system optimization, "online and offline" education platform structures, campus safety culture building ways, gradually achieve the college students' safety awareness, safety prevention measures, safety management system, safety skills and so on, to provide a solid foundation for the cultivation of high quality compound talents [7].

\section{REFERENCES}

[1] Yuye Sun. Research on the construction of safety culture in Higher Vocational Colleges.2014 modern enterprise education [J]. (2): 225-225.

[2] Fuqiang Yang etc.. Colleges and universities in the public elective course of "College Students' safety culture" practice and exploration [J]. Experimental technology and management, 2013 (12): 184-186.

[3] Yue Rong. Research on the public safety education of university students [D]. Suzhou: Soochow University, 2011

[4] Zhaodong Ji. The thought of university campus safety culture construction [J] Family education world, 2013 (03): 20-25

[5] Changchen Zou. The campus safety culture connotation, function and construction[J] Hunan forum, 2005 (02): 87-88

[6] Qingxin Wei. Reflections on the construction of safety culture in Colleges and universities [J]. China Public Security (Academic Edition), 2005 (03): 91-92

[7] Qingfen Bao, Xiaohong Zhang. Reflections on the construction of campus safety culture in Colleges and universities [J]. safety and environmental engineering, 2006,13 (2): 91-93 